\title{
Practical ways for coaches to reduce their stress and avoid burnout
}

\author{
Robert Pearson, Timothy Baghurst*
}

Florida State University, Tallahassee, USA

* Corresponding author: tbaghurst@fsu.edu

\begin{abstract}
Stress and the potential for burnout are a very real and present concern for coaches at all levels of competition. However, while stress is ever-present, many coaches have never received education or training on how to effectively cope with experienced stress. Therefore, the purpose of this article is to present practical ways for coaches to reduce stress and avoid burnout. A brief review of stress, burnout, and the stressors coaches often face are presented. This is followed by methods to help mitigate stress and avoid burnout including best practices for physical activity, meditation, connecting with mentors, connecting with family, renewal, setting limits, saying no, continuing education, and some unexpected methods to reduce stress. All coaches will experience stress, and its recognition, combined with the skills and tools needed to moderate its effects aid in longer and more successful coaching careers.
\end{abstract}

\section{KEYWORDS}

coaching; coach; stress management; sleep; meditation; exercise

DOI

10.14712/23366052.2020.13

\section{Practical ways for coaches to reduce their stress and avoid burnout}

Wake up, coach, plan training, teach, complete other assigned duties and tasks, sleep a few hours, and repeat. This, or a similar pattern, may be familiar to coaches; the grind of a daily routine without balance repeatedly exposes them to stressors that, unless moderated in some way, can lead to burnout (Pearson et al., 2020). Research in the past decade has determined burnout is more than an emotional state; it is an employee's response to job stressors. These stressors, especially through long-term exposure, result in decreased productivity, feelings of role ambiguity and conflict, job overload, and emotional exhaustion (Purvanova \& Muros, 2010; Sisley, 1987; Vladut \& Kallay, 2010). Therefore, if a coach is experiencing levels of stress that cannot be balanced or moderated, burnout is likely to occur.

Coaches are highly visible members of the community and often face job performance demands not found in other professions (Schroeder, 2010; Van Mullem, 2015). Winning or losing is a very visible performance indicator of success, and when com-

(C) 2020 The Authors. This is an open-access article distributed under the terms of the Creative Commons Attribution License (http://creativecommons.org/licenses/by/4.0), which permits unrestricted use, distribution, and reproduction in any medium, provided the original author and source are credited. 
bined with balancing the vast array of job requirements associated with the coaching profession, creates a stressful work environment (Rundle-Thiele \& Auld, 2009). Among other duties coaches may serve as a substitute parent, disciplinarian, academic tutor, tactician, mentor, and friend (Davis, 2005). Coaches can be challenged to aid transitioning young adults into a new athletic and academic environment, and perhaps even a new culture or language when working with international athletes (Baghurst et al., 2018). Coaches are also charged with creating group cohesion, a sense of purpose, and developing the life skills of their athletes (Saavedra, 2013). These are just a few of the many behaviors, skills, and characteristics expected of those in the coaching profession that must be balanced with winning.

Employment as a coach is tenuous at best, and the job expectations of the profession may lead to stress and eventually burnout (Kelley \& Baghurst, 2009; Tashman et al., 2010). Stress occurs when the demands of the job or a given situation exceed perceived capabilities and resources for an individual to be successful (Hjälm et al., 2007). Extreme stress, or repeated exposure to stressors, can lead to psychological, physical, and sociological concerns that in turn lead toward burnout. For example, psychological consequences include emotional exhaustion, frustration, reduced personal accomplishment or disillusionment, and negative feelings and beliefs (Freudenberger, 1974; Maslach \& Jackson, 1982; Sonnentag \& Jelden, 2009; Stickle \& Scott, 2016). Physical ramifications such as fatigue, heart attacks, strokes, ulcers, substance abuse, and increased morbidity may also occur (Frey, 2007; Mazerolle et al., 2008). Socially, the coach may experience negative consequences such as interference with daily living, lack of a positive work-life balance, and difficulty with interpersonal relationships (Olusoga et al., 2009; Tekano et al., 2011).

Stress and burnout in coaches is well-documented throughout a variety of sports (Olusoga et al., 2019). With repeated stress, or extreme bouts of stress, and without the appropriate resources to cope with the stress, a coach may leave the profession (Anderson, 2010; Bradford \& Keshock, 2009; Coy \& Masterson, 2007; Kelley \& Baghurst, 2009). Therefore, to battle stress, a coach must make a concerted effort to schedule time toward stress reduction and control (Stickle \& Scott, 2016). The nature of the coaching profession is fluid and requires coaches to confront issues as they arise. This means taking time from a current task to battle a new crisis, whether an athlete walks into the office with a personal problem, or a contest needs to be rescheduled because of weather. Therefore, coaches must consider the time necessary to combat stress as sacred and not to be interrupted, or stress may continue to build.

Given that stress is ever-present within the coaching profession, and coaches across all demographics and experience levels report experiencing stress of different kinds (Pearson et al., 2020), it is important to consider what and how stress coping mechanisms could be adopted by coaches to help mitigate these stressors. Therefore, based on previous research and application, and presented in no specific order, we offer a variety of guidelines and suggestions that coaches can utilize to establish a personal tool kit of stress reduction techniques.

\section{Exercise}

Exercise can be a valuable moderator of stress in coaching (Frey, 2007). It is interesting that very few empirical articles report coaches using exercise or physical activity 
as a buffer of stress, yet exercise has been found to be very valuable in alleviating stress (Lawrence, 2005). Although age and injury may affect how much or how hard a coach exercises (Baghurst \& Diehl, 2016), regular physical exercise even in the form of walking or the use of an elliptical provides physiological and psychological benefits (Michaelis, 2013).

Many sports are conducted indoors, and coaches likely spend considerable time in indoor offices. Therefore, coaches may be susceptible to a vitamin D deficiency, which has also been linked to stress levels (Lansdowne \& Provost, 1998). Therefore, outdoor activity might be even more beneficial at reducing stress (Olafsdottir et al., 2017). Coaches should consider walks away from the training/competition facility, or consider engaging in low-impact outdoor activities such as yoga or tai chi.

\section{Meditation}

Coaches must take time away from everyone and everything. Meditation, or the use of relaxation techniques, can be used to reduce stress. Long-term mediation has been found to improve cognitive function and improve the body's physiological relaxation as measured by heart rate and galvanic skin response (Singh et al., 2012).

If new to mediation, find a place that is comfortable and calming. An office could suffice if there are no interruptions. Listening to a guided meditation tape, soothing music, or a guided app can be helpful. Headspace is a popular app that provides a variety of relaxation exercises.

To meditate, focus on posture, being comfortable, and breathing. Losing "focus" is normal, but efforts should be made to return to the task at hand, which is to take a break from daily living and working. Mediation can help avoid "future fret" (Small $\&$ Vorgan, 2019). Meditation helps with decision making and reduces worry about an unknown future (Stahl \& Goldstein, 2019).

\section{Connect with a mentor}

Whether formal or informal, a mentor can help. Although not a daily activity, conversing with a mentor can help serve as a motivator and an impartial advisor (Sciarappa, 2010). In their study, Christie Jr. and Baghurst (2017) reported mentors provided assistance with personal and professional success, breaking through barriers, and assisted in developing leadership skills. Further, a strong correlation exists between those involved in a mentorship experience and a heightened sense of well-being (Kutsyuruba et al., 2019). Kutsyuruba and colleagues also reported that those who did not connect with a mentor revealed a significantly lower sense of well-being.

Time is a precious commodity in the workplace (Davies, 2014). Past research specific to those employed in the field of education found striking a balance between personal and professional duties is a difficult task (Lester, 2015). However, if a mentor strongly supports a mentee's healthy work-life balance, the less likely they are to experience associated stress (Nielson et al., 2001).

It is important to recognize that mentors may also be busy and experiencing stress themselves. Therefore, be cognizant of how often and when conversations take place. Recognize that within a scale that values time, a mentor's time is more valuable than that of the mentee's. Therefore, find ways to show appreciation for the mentor giving 
up that time. Sending a handwritten note of thanks or a small gift goes a long way to ensure that the value is appreciated.

One coach, cited by Baghurst (2020), summarized why finding a mentor and networking was important.

Make an honest effort in getting to know other coaches, especially those that are veterans and have been around awhile. Most coaches will be open to you and give advice and ideas. It will also help you to network and be more involved in your profession. Some of the best tips, advice, scouting reports, and practice procedures came from veteran coaches. Do not be scared or embarrassed to ask for some help (p. 544).

\section{Connect with family}

The conflict between work and family directly or indirectly affects a large portion of the global population (Kossek \& Lee, 2017). Even those who are single will experience stress associated with family life, as they may be sons or daughters or are part of a group of friends that functions as a family (Kossek \& Lee, 2017).

Coaches are no exception to this work/family conflict. Time management is one of the most difficult challenges of a coach, and sometimes time is given to work over other commitments, which leads to stress and burnout (Pearson et al., 2020). Therefore, it is important to make committed efforts to connect with family on a regular basis. Similar to connecting with a mentor, connecting with family can bring immediate improvement to mood states (Karakas et al., 2004). It may be one of the greatest joys in life and helps to build connections among and between generations toward a more shared future (Murakami \& Jacobs, 2017).

Connecting deeply with a spouse, partner, family member, or friend helps to relieve stress in many ways, including sharing the challenges and burdens that might be being experienced. The feeling of profound connectedness with someone is calming (Eliuk \& Chorney, 2017). So, whether face-to-face, on the phone, the computer, or by any other means, coaches should make efforts to connect regularly with family members, especially if they are those who can aid in reducing experienced stress.

\section{Prioritize and set limits}

It can be easy for coaches to take on too many responsibilities (Lyst, 2019). However, it is important coaches set realistic limits of what you can accomplish (Valcour, 2016). Stress is created by expectations, whether personal or those placed on an individual by others, and is a key element in coaching stress (Radke, 2012).

Coaches should consider using day planners or task lists to get through the day. Calendar software or apps can also help to establish schedules and routines, including times for breaks (e.g., relaxation/meditation). Prioritizing tasks also assist in achieving work goals efficiently. Baghurst (2019) presented the suggestion of using the Eisenhower Box to make decisions. Decisions are assigned as Urgent/Important (e.g., meeting a project guideline), Important/Not Urgent (e.g., family time), Not Important/ Urgent (e.g., booking a hotel), and Not Important/Not Urgent (e.g., using social media). Developing a plan and prioritizing accordingly will assist in time management, efficiency, and ultimately lower levels of stress. 


\section{Say no}

If tasks have been prioritized tasks and limits set, saying no to extra tasks or assignments is important, especially if not part of the job description. Saying yes can come at a cost of time and additional stress. A coach may feel pressured into saying yes too frequently, especially if the coach is new to the position or is experiencing job insecurity. In addition, saying no might create feelings of worry as it pertains to a relationship with a superior, colleague, or even recruit. However, saying no is an important word to accept and use (Ury, 2007).

Practicing saying no may be of benefit. "I just can't commit to that right now", "I would love to help, but I have other priorities", or "Could you ask me again in a week's time? I am right in the middle of another project" are all example responses that could be offered. Regardless of the phrase used, learning to say no should be required of all coaches, and may be one of the most effective ways for leaders to shape their program or organization (Jamison \& Neubauer, 2019).

\section{Renewal}

Coaches should take time to rest and renew (Valcour, 2016). Vacation time should be used, not excused. For many coaches, this may prove difficult, especially if coaching multiple sports in a school or club setting or recruiting in the off-season. However, delegation of duties to others such as an assistant on occasion creates a time window and also provides the assistant with opportunity for growth.

Sleep is also an important component of renewal. Even a single night of sleep deprivation may result in poor decision-making and impact vigilance and motor skills (Stojanoski et al., 2019). Lastella and colleagues (2017) measured the sleep quantity and quality of a coach compared to his athletes and reported that the coach obtained less sleep with poorer quality than his athletes, markedly so before significant games. Rest and renewal serve to reduce exposure to stressors and help avoid burnout (Sonnentag \& Jelden, 2009).

Spending some time on a favorite hobby can also reduce stress (Sabo, 2011). Examples of such hobbies include, but are certainly not limited to reading, listening to music, knitting, painting or other art projects, playing cards, board games or computer games, or watching a movie. Caution should be given to electronic forms of relaxation such as TV shows, movies, or computer games, as they can be addictive. For example, Carlston et al. (2006) reported online gaming as addictive as gambling; therefore, if selecting a form of relaxation that could be addictive, set boundaries and limits. Whatever activity chosen, it should bring pleasure and reduce stress.

\section{Continuing education}

The more competent an individual feels about the task at hand, the lower the level of stress experienced (Aldrup et al., 2017). Therefore, coaches should seek opportunities to improve their skillset. Attending clinics, enrolling in academic programs, or even reading or watching educational content aids in developing new knowledge and ideas. Some universities offer courses online without fees, or others offer them for a more formal certificate. For example, the FSU COACH Center (n.d.) at Florida State University offers coaching certifications as well as free online educational content via YouTube (www.youtube.com/fsucoach). Of course, coaches must ensure that 
there is sufficient time to achieve long-term educational commitments. Completing an academic credential can be stressful in and of itself (Hirsh et al., 2020); therefore, support systems should be built-in to aid in ensuring that stress levels do not exceed the resources in place to manage them.

\section{Unexpected ways to alleviate stress}

A literature search of stress reduction methods for coaches revealed some unexpected methods that may or may not be beneficial based on the individual preferences of the coach. For example, research suggests that chewing gum has been found to lower stress, anxiety, and reduce fatigue (Smith et al., 2012). However, long-term chewing or chomping gum may result in jaw discomfort (Farella et al., 2001). Laughter and humor have been found to reduce stress (Yoshikawa et al., 2018), and viewing a video of a stand-up routine or reading the comics section of the newspaper will aid in relaxation and mood improvement. A final unexpected method to reduce stress is to watch fish swim in an aquarium (Cracknell et al., 2015). Viewing the animals swim, especially if the population of fish is larger, was found to increase a sense of well-being. Ultimately, there are a variety of ways to reduce stress, but each individual should find ways that work for them.

\section{CONCLUSION}

The consequences of stress in the coaching profession can be severe. Stress exacts a psychological and physical toll on the body that includes a variety of personal, physical, and psychological effects (Bryant, 1992; Ferraro \& Nuriddin, 2006; Khan, 2011; Kim et al., 2011; Olusoga et al., 2009; Tekano et al., 2011). Stress also adversely affects decision-making skills and quality of life (Ferraro \& Nuriddin, 2006).

When, not if, a coach experiences stress, it may negatively affect work demeanor, attitude, and performance. Knowing stress exists in the coaching profession is the first step to confronting the dangers. Presented were a variety of methods to reduce levels of stress, but it should be noted that what works for each coach will differ. However, coaches should understand that all coaches will experience stress, even if the type that each might experience differs (Pearson et al., 2020). Therefore, coaches must develop stress reduction strategies that mitigate stress, or burnout will almost certainly occur.

\section{REFERENCES}

Aldrup, K., Klusmann, U., \& Lüdtke, O. (2017). Does basic need satisfaction mediate the link between stress exposures and well-being? A diary study among beginning teachers. Learning and Instruction, 50, 21-30.

Anderson, D. L. (2010). Organization development: The process of leading organizational change. Thousand Oaks, CA: Sage Publications.

Baghurst, T. (2019). Learning from coaches. In: T. Baghurst (Ed.), Fundamentals of coaching for sports performance. London: Routledge.

Baghurst, T. (2019). Lifestyle wellness. In: T. Tapps, B. Dorrell, M. Symonds, \& T. Baghurst (Eds.), Health and wellness: A practical workbook. Dubuque, IA: Kendall Hunt.

Baghurst, T., \& Diehl, B. (2016). Shaping up the profession: The importance of modeling health and fitness as coaches. International Sport Coaching Journal, 3(3), 349-354. 
Baghurst, T., Fiaud, V., Tapps, T., \& LaGasse, A. (2018). Considerations when coaching the international athlete. International Journal of Kinesiology in Higher Education, 2(3), $76-86$.

Bradford, S. H., \& Keshock, C. M. (2009). Female coaches and job stress: A review of the literature. College Student Journal, 43(1), 196-199.

Bryant, W. K. (1992). Human capital, time use, and other family behavior. Journal of Family and Economic Issues, 13(4), 395-405.

Carlston, D. L., Baghurst, T., Hugman, S., Johnson, L., \& Snyder, A. (presented 2006, March). Online gaming: Addictive quality among young adults. Presentation at 51st Annual Meeting, Southwestern Psychological Association, Memphis, TN. (Regional).

Christie Jr., E., \& Baghurst, T. (2017). College mentoring: Alumni views on programme efficacy in shaping leadership ability. International Journal of Evidence Based Coaching and Mentoring, 15(1), 169-185.

Coy, B., \& Masterson, G. (2007). Hiring a winning coach and coping with stress. Coach and Athletic Director, 76(9), 32-35.

Cracknell, D., White, M. P., Pahl, S., Nichols, W. J., Depledge, M. H. (2016). Marine biota and psychological well-being: A preliminary examination of dose-response effects in an aquarium setting. Environment and Behavior, 48(10), 1242-1269.

Davies, N. (2014). The work-life balance. Nursing Standard, 29(2), 63.

Davis, P. G. (2005). Performance appraisal for coaches. Paper presented at the ICCE Coaching Conference Hong Kong, China.

Eliuk, K., \& Chorney, D. (2017). Calming the monkey mind. International Journal of Higher Education, 6(2), 1-7.

Farella, M., Bakke, M., Michelotti, A., \& Martina, R. (2001). Effects of prolonged gum chewing on pain and fatigue in human jaw muscles. European Journal of Oral Sciences, 109(2), $81-85$.

Ferraro, K. F., \& Nuriddin, T A. (2006). Psychological distress and mortality: Are women more vulnerable? Journal of Health and Social Behavior, 47(3), 227-241.

Freudenberger, H. J. (1974). Staff burnout. Journal of Social Issues, 30(1), 159-165.

Frey, M. (2007). College coaches' experiences with stress: Problem solvers have problems, too. The Sport Psychologist, 21(1), 38-57.

FSU COACH. (n.d.). FSU Coach. Retrieved from https://fsu-coach.fsu.edu.

Hirsch, J. D., Nemlekar, P., Phuong, P., Hollenbach, K. A., Lee, K. C., Adler, D. S., \& Morello, C. M. (2020). Patterns of stress, coping and health-related quality of life in doctor of pharmacy students. American Journal of Pharmaceutical Education, 84(3), 7547.

Hjälm, S., Kenttä, G., Hassménan, P., \& Gustafsson, H. (2007). Burnout among elite soccer coaches. Journal of Sport Behavior, 30(4), 415-427.

Jamison, L. S., \& Neubauer, B. (2019). Leadership lessons from the field: Leading by saying “No." Military Medicine, 185(1-2), 12-13. https://doi-org.proxy.lib.fsu.edu/10.1093 /milmed/usz273.

Karakas, F., Lee, M. D., \& MacDermid, S. M. (2004). A qualitative investigation into the meaning of family well being from the perspective of part time professionals. Equal Opportunities International, 23(1-2), 57-77.

Kelley, B. C., \& Baghurst, T. (2009). Development of the coaching issues survey. The Sports Psychologist, 23(3), 367-387.

Khan, S. (2011). Relationship of job burnout and type-A behavior on psychological health among secretaries. International Journal of Business and Management, 6(6), 31-38.

Kim, H., Ji, J., \& Kao, D. (2011). Burnout and physical health among social workers: A threeyear longitudinal study. Social Work, 56(3), 258-268.

Kossek, E. E., \& Lee, K. H. (2017). Work-family conflict and work-life conflict. In: Oxford Research Encyclopedia of Business and Management. Oxford University Press. 
Kutsyuruba, B., Godden, L., \& Bosica, J. (2019). The impact of mentoring on the Canadian early career teachers' well-being. International Journal of Mentoring and Coaching in Education, 8(4), 285-309.

Lansdowne, A., Provost, S. (1998) Vitamin D3 enhances mood in healthy subjects during winter. Psychopharmacology, 135(4), 319-323.

Lastella, M., Roach, G. D., Halson, S. L., Gore, C. J., Garvican-Lewis, L. A., \& Sargent, C. (2017). Sleep at the helm: A case study of how a head coach sleeps compared to his team. International Journal of Sports Science \& Coaching, 12(6), 782-789.

Lawrence, D. (2005). The complete guide to exercising away stress. A \& C Black Publishers, $160 \mathrm{p}$. Lester, J. (2015). Cultures of work-life balance in higher education. Journal of Diversity in Higher Education, 8(3), 139-156.

Lyst, R. (2019). Coaching collegiate sports. In: T. Baghurst (Ed.), Fundamentals of coaching for sports performance. New York: Routledge.

Maslach, C., \& Jackson, S. E. (1986). The Maslach Burnout Inventory (2nd ed.). Palo Alto, CA: Consulting Psychologist Press.

Mazerolle, S. M., Bruening, J. E., \& Casa, D. (2008). Work-family conflict part 1: Antecedents of work-family conflict in national collegiate athletic association division I-A certified athletic trainers. Journal of Athletic Training, 43(5), 505-512.

Michaelis, B. (2013). Your next big thing: Ten small steps to get moving and get happy. Wolf Street Press.

Murakami, K., \& Jacobs, R. L. (2017). Connecting dots: Family reminiscence. In: Å. Mäkitalo, P. Linell, \& R. Säljö (Eds.), Advances in cultural psychology: Constructing human development. Memory practices and learning: Interactional, institutional and sociocultural perspectives (pp. 293-315). Information Age Publishing.

Nielson, T. R., Carlson, D. S., \& Lankau, M. J. (2001). The supportive mentor as a means of reducing work-family conflict. Journal of Vocational Behavior, 59(3), 364-381.

Olafsdottir, G., Cloke, P., Vögele, C. (2017). Place, green exercise and stress: An exploration of lived experience and restorative effects. Health \& Place, 46, 358-365.

Olusoga, P., Bentzen, M., \& Kentta, G. (2019). Coach burnout: A scoping review. International Sport Coaching Journal, 6(1), 42-62.

Olusoga, P., Butt, J., Hays, K., \& Maynard, I. (2009). Stress in elite sports coaching: Identifying stressors. Journal of Applied Sports Science, 21(4), 442-459.

Pearson, R. T., Baghurst, T., \& Mwarumba, M. (2020). Stress and burnout experienced by intercollegiate swimming head coaches. International Sport Coaching Journal, 1-7. https:// doi.org/10.1123/iscj.2019-0030.

Purvanova, R. K., \& Muros, J. P. (2010). Gender differences in burnout: A meta-analysis Journal of Vocational Behavior, 77(2), 168-185.

Radke, K. (2012). Be your best without the stress: It's not about the medal. Motivational Press.

Rundle-Thiele, S., \& Auld, C. (2009). Should I stay or should I go? Retention of junior sport coaches. Annals of Leisure Research, 12(1), 1-21.

Saavedra, L. K. (2013). Effective team building: The role of coaches. Strategies, 26(4), 3-6.

Sabo, B. (2011). Reflecting on the concept of compassion fatigue. The Online Journal of Issues in Nursing, 16(1).

Schroeder, P. J. (2010). Changing team culture: The perspective of ten successful head coaches. Journal of Sport Behavior, 33(1), 63-88.

Sciarappa, K. (2010). Mentor connections. Principal, 90(1), 36-38.

Singh, Y., Sharma, R., \& Talwar, A. (2012). Immediate and long-term effects of meditation on acute stress reactivity, cognitive functions, and intelligence. Alternative Therapies in Health and Medicine, 18(6), 46-53.

Sisley, B. L. (1987). Preventing burnout in teacher coaches. Journal of Physical Education, Recreation, \& Dance, 58(8), 71-75. 
Small, G., \& Vorgan G. (2019). The small guide to anxiety. Humanix Books.

Smith, A. P., Chaplin, K., \& Wadsworth, E. (2012). Chewing gum, occupational stress, work performance and well-being. An intervention study. Appetite, 58(3), 1083-1086.

Sonnentag, S., \& Jelden, S. (2009). Job stressors and the pursuit of sport activities: A day-level perspective. Journal of Occupational Health Psychology, 14, 165-181.

Stahl, B., \& Goldstein, E. (2019). A mindfulness-based stress reduction workbook. New Harbinger Publications.

Stickle, F. E., \& Scott, K. (2016). Leadership and occupational stress. Education, 137(1), 27-38.

Stojanoski, B., Benoit, A., Van Den Berg, N., Ray, L. B., Owen, A. M., Zandi, A. S., Quddus, A., Comeau, F. J. E., \& Fogel, S. M. (2019). Sustained vigilance is negatively affected by mild and acute sleep loss reflected by reduced capacity for decision making, motor preparation and execution. Sleep, 42(1), 1-9.

Tashman, L. S., Tenenbaum, G., \& Eklund, R. (2010). The effect of perceived stress on the relationship between perfectionism and burnout in coaches. Anxiety, Stress, \& Coping, 23(2), 195-212.

Tekano, K., Sakamoto, S., \& Tanno, Y. (2011). Ruminative and reflective forms of self-focus: Their relationships with interpersonal skills and emotional reactivity under interpersonal stress. Personality and individual Differences, 51(4), 515-520.

Ury, W. (2007). The power of a positive no: How to say no and still get to yes. Bantam.

Valcour, M. (2016). Beating burnout. Harvard Business Review, 94(11), 98-101.

Van Mullem, P. (2015). Developing a systematic evaluation for coaches, a commentary on 'Coach Evaluation' by Gilham, Hansen and Brady. International Sport Coaching Journal, 2(2), 203-205.

Vladut, C., \& Kallay, E. (2010). Work stress, personal life, and burnout. Causes, consequences, possible remedies: A theoretical review. Cognition, Brain, Behavior, 14(3), 261-280.

Yoshikawa, Y., Ohmaki, E., Kawahata, H., Maekawa, Y., Ogihara, T., Morishita, R., Aoki, M. (2018). Beneficial effect of laughter therapy on physiological and psychological function in elders. Nursing Open, 6(1), 93-99. 